\title{
Diagnostic effectiveness of serological tests for the detection of brucellosis antibodies
}

\author{
E.I. Kasymov*, B.K. Otarbayev, G.D. Ilgekbayeva, I.N. Galymzhan, and T.M. Kydyrkhanov \\ Kazakh National Agrarian Research University, Abai st. 8, Almaty, Kazakhstan
}

\begin{abstract}
The article reflects the results of testing various diagnostic tests (ST, RA, CFT, BRT, IHA and ELISA) in the diagnosis of brucellosis in cattle, where animals are subjected to serological tests without the use of a vaccine. Antibodies against brucellosis were detected in diagnostic titer in ST in $100 \%$ and in ELISA in $96 \%$ of cases. The difference between the rates of these reactions was statistically insignificant $(\mathrm{P}>0.1)$. ICA is significantly inferior to these two tests. This difference turned out to be significant, that is, significant $(\mathrm{P}<0.01)$. The lowest rates are set for RA, RBT and CFT. For the diagnosis of brucellosis, of all the tests tested, ST and ELISA turned out to be the most sensitive, and of these two tests, the most accessible for practice is ST.
\end{abstract}

\section{Introduction}

Bovine brucellosis is a widespread zoonotic disease in many countries of the world that causes great economic damage to livestock and poses a serious threat to human health [1-3]. One of the main methods of rehabilitation of unsuccessful foci of brucellosis in cattle in our republic and some countries of the CIS and far abroad is the systematic conduct of serological studies followed by the slaughter of reacting animals and appropriate sanitary measures [1, $2,4]$. The success of this recovery method depends mainly on the early detection of all infected animals. Therefore, the largest number of studies has been devoted to the study of the diagnostic value of the agglutination reaction (RA), the complement fixation reaction (CFT) and its long-term variant (LTV), the Bengal rose test (BRT). Over time, it turned out that none of them, even the complex application of these tests, does not always allow the identification of all infected animals in a short time. In addition, the complex application of these methods when carrying out health-improving activities has become very difficult and time-consuming $[2,5,6]$.

As a result of the search for highly sensitive diagnostic methods available for wide practice, E.Engval and P. Perlman in 1972 developed an enzyme-linked immunosorbent assay (ELISA) [7], and in $1981 \mathrm{~T}$. Saiduldin - a conglutinating complex fixation test (CCFT) $[5,6,8]$. Currently CCFT is renamed after the author's name - Saiduldin Test (ST) [9-11].

According to the author and his followers, the ST fully confirms the overall positive results of RA, CFT, CLFT, RBT for brucellosis. In addition, ST can additionally identify infected animals in a herd $[2,5,6,9-11]$. In a special experiment on 46 cows with similar

\footnotetext{
*Corresponding author: yerken.kassymov@mail.ru
} 
signs of serological reactions, biological analysis in guinea pigs revealed brucellosis in $54.3 \%$ of cases $[5,6]$. The specificity of ST was confirmed by DPT with the O-PS antigen produced by "Vector", Novosibirsk [12], as well as by studying the dynamics of indications for additional reoperation in animals with negative AT and CFT. In the last experiment, 92 animals with current results from 4912 cows and heifers studied (with heifers at the age of 46 months and before mating are immunized with the anti-brucellosis vaccine from strain 82 , and the cows are systematically vaccinated. Serological test for AT, CFT and ST) isolated and kept separate from the main herd. On one farm, during 136-154 days, they were examined 6 times (every 15-30 days), as a result of which the diagnosis of brucellosis was confirmed in $91.3 \%$ of cows and $83 \%$ of heifers. On another farm, $70 \%$ of the isolated animals were diagnosed within 90 days. In these dysfunctional farms, all herds for AT, CFT and ST were studied with isolation of animals that reacted with ST, which allowed the second and third diagnostic tests to be negative for AT, CFT and RBT. Twofold negative results of these tests allowed for a short period of time ( 8 months) to cure the herd of brucellosis [9]. In terms of sensitivity, ST in the diagnosis of brucellosis is not inferior to ELISA with an immunoperoxidase conjugate produced by the RRIEM named Gamaley [2].

ST uses the same components and equipment as CFT, except for the replacement of guinea pig complement with bovine serum containing conglutinin, which actively reacts with complement, a fixed antigen-antibody complex. Since complement and conglutinin act as a single functional system, the serum that is the source of these factors, T.Saiduldin called it "gluing" [8]. To introduce ST into veterinary practice, industrial production of dry conglutinating serum was established [13], and its production tests were carried out in veterinary laboratories by examining 81056 samples of bovine serum for brucellosis in ST in in four republics of the CIS. At the same time, ST with the use of a dry preparation was highly effective and accessible for practice. The diagnosis of brucellosis by AT, CFT and RBT was confirmed by ST in $95.6 \%, 99.3 \%$ and $70.7 \%$, respectively [14].

Recently, an immunochromatographic assay (ICA) and an enzyme-linked immunosorbent assay (ELISA) have been proposed by "Bru Ltflow Ab" to detect antibodies to the causative agent of brucellosis. The diagnostic value of ST in comparison has not previously been studied.

The purpose of the research. Testing of the diagnostic values of serological methods (ST, AT, RBT, CFT, ICA and ELISA) in the diagnosis of brucellosis of cattle in farms and settlements unfavorable for this disease, where animals have not been subjected to antibrucellosis vaccinations.

\section{Materials and methods}

Complex serological methods were used to study 310 blood serum samples from cattle.

BRT, RA, CFT for brucellosis were carried out according to the existing guidelines. ST according to the manual for setting and recording the Saiduldin Test (ST) in the diagnosis of brucellosis in cattle, approved by Director of the Department of Veterinary Surveillance of the Ministry of Agriculture of the Republic of Kazakhstan dated December 27, 2000. We used the ICA kit for the detection of antibodies to the causative agent of brucellosis "Bru Ltflow Ab" (UAB "LT Biotech" IK 302303586 Rugiq 21-24, LT-08419, Vilnius Reg. Nr. 127918, VI Registry centras Vilniaus fillialas), as well as B. Brucella Ab ELISA (Anigen enzyme immunoassay kit for the presence of antibodies to Brucella. South Korean production BioNote 22 SamsungIro 4-gil, Hwaseong-si, Gyeonggi-do 445-170 Republic of Korea).

Statistical processing of the results of serological studies was carried out according to the method of T. Saiduldin [8]. 


\section{Research results and discussion}

When determining the diagnostic effectiveness of serological reactions, titers of 1:5 in four crosses and higher were taken as a positive ST result. In a brucellosis-unfavorable site, the results of complex serological tests (ST, AT, CFT, RBT, ICA and ELISA) examined 310 blood serums of cattle aged 1 year and older. The results are shown in the table and in Figure 1.

Table. 1. Comparative results of serological reactions at a brucellosis problem

\begin{tabular}{|c|c|c|c|c|c|c|}
\hline \multirow[t]{2}{*}{ № } & \multicolumn{6}{|c|}{ Name of the reaction } \\
\hline & ST & CFT & RBT & AT & ICA & ELISA \\
\hline 1 & $1: 320$ & $1: 80$ & + & $1: 400$ & ++++ & $1: 800$ \\
\hline 2 & $1: 160$ & $1: 40$ & - & - & ++++ & $1: 200$ \\
\hline 3 & $1: 20$ & - & - & - & - & $1: 50$ \\
\hline 4 & $1: 20$ & - & + & - & ++ & $1: 50$ \\
\hline 5 & $1: 40$ & $1: 10$ & + & - & - & $1: 100$ \\
\hline 6 & $1: 80$ & $1: 20$ & - & - & ++ & $1: 200$ \\
\hline 7 & $1: 40$ & $1: 10$ & - & - & ++++ & $1: 100$ \\
\hline 8 & $1: 160$ & $1: 40$ & + & $1: 200$ & ++++ & $1: 400$ \\
\hline 9 & $1: 20$ & $1: 10$ & - & - & - & $1: 50$ \\
\hline 10 & $1: 10$ & - & - & - & - & - \\
\hline 11 & $1: 20$ & - & + & - & ++ & $1: 50$ \\
\hline 12 & $1: 80$ & $1: 20$ & - & - & ++ & $1: 200$ \\
\hline 13 & $1: 320$ & $1: 80$ & + & $1: 400$ & ++++ & $1: 800$ \\
\hline 14 & $1: 160$ & $1: 40$ & + & $1: 200$ & ++++ & $1: 400$ \\
\hline 15 & $1: 40$ & $1: 10$ & + & - & - & $1: 100$ \\
\hline 16 & $1: 20$ & - & - & - & - & $1: 50$ \\
\hline 17 & $1: 40$ & $1: 10$ & + & - & +++ & $1: 100$ \\
\hline 18 & $1: 10$ & - & - & - & - & $1: 50$ \\
\hline 19 & $1: 640$ & $1: 80$ & + & $1: 200$ & +++ & $1: 800$ \\
\hline 20 & $1: 320$ & $1: 80$ & + & $1: 200$ & ++++ & $1: 800$ \\
\hline 21 & $1: 40$ & $1: 20$ & + & - & +++ & $1: 200$ \\
\hline 22 & $1: 320$ & $1: 40$ & + & $1: 100$ & +++ & $1: 400$ \\
\hline 23 & $1: 80$ & $1: 80$ & + & $1: 200$ & ++++ & $1: 200$ \\
\hline 24 & $1: 320$ & $1: 80$ & + & $1: 100$ & ++++ & $1: 400$ \\
\hline 25 & $1: 20$ & - & - & - & - & $1: 50$ \\
\hline 26 & $1: 160$ & $1: 20$ & + & - & ++++ & $1: 200$ \\
\hline 27 & $1: 40$ & $1: 10$ & - & - & ++ & $1: 50$ \\
\hline $\begin{array}{l}\text { Middle } \\
\text { Title }\end{array}$ & $\begin{array}{c}260 \\
+22,3 \\
-18,2\end{array}$ & $\begin{array}{c}15 \\
+18,1 \\
-15,3\end{array}$ & & $\begin{array}{c}50 \\
+14,1 \\
-12,3\end{array}$ & & $\begin{array}{c}150 \\
+18,1 \\
-15,3\end{array}$ \\
\hline
\end{tabular}

By all reactions, brucellosis was diagnosed in 27 animals. In conventional reactions, brucellosis was diagnosed in RBT - 16; AT - 6; CFT - 20, and in ICA - 19. Summarized positive results of these tests were confirmed by ELISA (22), and 4 sick animals were additionally identified. In ST, these positive results are $100 \%$ confirmed. In addition, they additionally reacted to brucellosis in ST - in one animal. As a result of statistical processing, the average titer in ST was 1: 260, and in CFT - 1:15, AT -1: 50, this difference turned out to be significant $(\mathrm{P}<0.01)$. In ELISA, the average titer was $1: 150$, this difference between the ST result turned out to be statistically insignificant $(\mathrm{P}>0.1)$. 


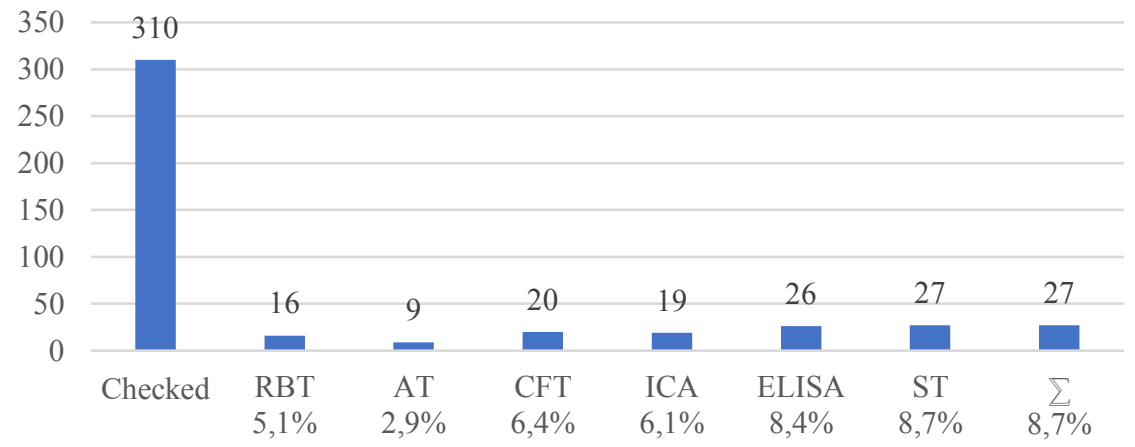

Fig. 1. Percentage of positive results in various serological tests

As can be seen from Figure 1, positive results as a percentage were registered in the AT $-2.9 \%$ (9), in the CFT - 6.4\% (20), in the RBT - 5.1\% (16), in the ICA - 6,1\% (19), ELISA $8.4 \%$ (26) and in ST $-8.7 \%$ (27) cases. The total positive results of complex tests as a percentage was $8.7 \%$.

\section{Conclusion}

Anti-brucellosis antibodies were found in diagnostic titers for ST in $100 \%$, and in ELISA in $96 \%$ of cases. The difference between the indicators of these reactions was statistically insignificant $(\mathrm{P}>0.1)$. ICA was somewhat inferior to these tests. The lowest rates were established for AT, RBT and CFT. Thus, the results of ST and ELISA significantly exceeded the indicators of other reactions (ICA, AT, RBT and CFT). This difference turned out to be significant, that is, significant $(\mathrm{P}<0.01)$. For the diagnosis of brucellosis, of all the tests tested, ST and ELISA turned out to be the most effective, and of these two tests, ST is the most effective and accessible for practice.

\section{References}

1. Wold Organization for Animal Health Terrestrial Manual Chapter 2.1.4. Brusellosis. OIE (2016)

2. Y. Kassymov, S. Zhumagalikyzy, Academic journal, World Academy of Science, Engineering and Technology 80, 247-248 (2011)

3. A.A. Ergin, Brucellosis; Diagnostic and theraheutic challenges, Congress materials, 2nd International Congress of Veterinary Microbiology, 114-116, 16-19 October Sherwood breezes resort - Lara, Antalya (2018)

4. Y. Iejla, Y. Ozeno, E. Toni, Seroprevalence brusellosis in Bosnia and Herzegovina, Congress materials, 2nd International Congress of Veterinary Microbiology, 16-19 October, Lara, Antalya (2018)

5. T.S. Saiduldin, Zh. Microbiology, Epidemiology and Immunobiology, 3, 13-19 (1981)

6. T.S. Saiduldin, Veterinary medicine, 2, 69-71 (1981) 
7. G.G, Alton, Lois M. Jones, D.E. Pietz, World Health Organization \& Food and Agriculture Organization of the United Nations, Laboratory techniques in brucellosis, (1975) https://apps.who.int/iris/handle/10665/38676

8. T. Saiduldin, Fundamentals of Serology, 307 (LAP LAMBERT Academic Publishing, 2014)

9. S.A. Kalachev, Improvement of dysfunctional farms from brucellosis of cattle through systematic serological studies on Saiduldin's reactions in a complex of antiepizootic measures, 23 (Cand. dis. Almaty, 1998)

10. B.K. Otarbayev, Brucellezdi balau Yshin Saiduldin reactionasynyk componentterin dayarlau zhune standartau, vet., Gylymynyk candidates Gylymi drezhesine arnalgan dissertation, 99 (Almaty, 2008)

11. Guidance on the formulation and accounting of the Saiduldin reaction (ST) in the diagnosis of brucellosis in cattle, Approved, 27 (Director of the Department of Veterinary Surveillance of the Ministry of Agriculture of the Republic of Kazakhstan dated December, 2000)

12. E. Kassymov, Selma Iyisan, Sigilarda Brucella tanisinda kullanilan standart serologik testler ve konglutinasion complex fiksasion testi'nin AGP testi OPS antigen'le gore kontrolu, Enformasion Animal International, 77-80 (Stambul, Mayis, 1995)

13. T.S. Saiduldin, E.I. Kasymov, Dry conglutinating serum for the binding reaction of the conglutinating complex TU 10-09-89-90 Approved. Ch. ex. State Veterinary Commission of the Council of MinisteST of the USSR for procurement Moscow, 4, 18 (1990)

14. Yerken Kassymov, Production and application of dry conglutinating serum for CCB test, Congress materials. 2nd International Congress of Veterinary Microbiology, Sherwood breezes resort - Lara, Antalya, 56-58 (2018) 